Jayne Cox

is Director of Brook

Lyndhurst and leisure

consultant to Property Market

Analysis.

Keywords:

leisure consumer trends, lifestyles, leisure property
Regular feature

\section{Leisure property trends: Consumer spending and leisure futures}

Jayne Cox

Received: 10 April 2002

\begin{abstract}
This paper brings together evidence and data from recently published material to provide an overview of current thinking on leisure consumer trends and their implications for leisure property. The paper looks at: UK consumer spending trends in the aftermath of the September 11 attacks; expectations for economic growth over the short and medium term; and latest thinking about trends that will shape leisure preferences, lifestyles and destinations in the long term.
\end{abstract}

\section{INTRODUCTION}

At the end of 2001 the outlook for UK leisure consumer markets was far from certain, with growing fears about global recession, the legacy of foot-and-mouth disease and the psychological shock of the recent New York terrorist attacks. More alarmist commentators were suggesting that consumers would stay at home, stop spending and never travel again. More reasonable voices envisaged that the already slowing economy would simply slip into recession, of uncertain depth and duration, depending on the response of US consumers and businesses.

Three months into 2002, this paper examines the latest economic data on the performance of the economy and leisure consumer spending in $2001^{1}$ to indicate which of these scenarios is emerging. Further evidence is provided by a summary of various short- and medium-term forecasts for the economy, leisure sectors and property market, drawing on publications from the UK Treasury, market researchers and property agents.

While these headline indicators of the health of leisure markets are useful they also, clearly need to be considered alongside underlying drivers of change in lifestyles and leisure preferences when thinking about long-term leisure property assets. The last section of the paper, therefore, draws together evidence on long-term trends and summarises recent reports that comment on evolving lifestyle trends. The paper concludes with speculative comments on the implications of these trends for leisure property. 
Shock to consumer confidence
Consumer economy unexpectedly buoyant

\section{AFTER SEPTEMBER 11}

\section{Confidence shock}

Immediately after the attacks in September, the press was full of dire predictions about the possible impact on the economy, tourism, hospitality and leisure businesses in the UK. Some examples are listed below.

- A MORI poll published in The Times on 27 September showed economic optimism at its lowest level since 1980, with 64 per cent saying they thought the economy would worsen in the next year. $^{2}$

- The GFK Consumer Confidence Barometer survey for the European Union similarly recorded a significant fall in consumers' confidence about the economy. ${ }^{3}$

- The World Tourism Organisation reduced its estimate for growth in global tourism in 2001 by one percentage point, to 1.5-2 per cent. The British Tourist Authority predicted a fall of $£ 2.5$ bn in visitor revenue in the $\mathrm{UK}^{4}$

- A new survey of UK hoteliers by Ernst \& Young with the English Tourism Council, carried out in October 2001, reported that only 28 per cent of respondents expected an increase in customers in the following three months, compared to 64 per cent who had reported increased turnover in the previous three months. ${ }^{5}$

Initial indicators of performance appeared to confirm the worst fears, especially in the tourism sector. For example, air passenger arrivals to seven key UK airports fell by 10.6 per cent (year on year) in October 2001 and a further 12 per cent in November; ${ }^{6}$ a 50 per cent fall in visitors to the Tate Modern was reported ${ }^{7}$ and overseas holiday visitors to the UK fell by 34 per cent in November compared to a year earlier. ${ }^{8}$

\section{Strong consumer spending}

The economic out-turn for 2001 was, in the event, more positive than many had expected. Despite continuing weakness in the global economy and a number of deteriorating domestic indicators, the UK economy managed to avoid recession in the last quarter of 2001. Although GDP stopped growing in the final three months of 2001, domestic consumers remained relatively positive. Household consumer spending increased by 0.9 per cent in the last quarter of 2001 (and by 3.9 per cent over the year), ${ }^{9}$ and retail sales in December reached a five year high point, according to the British Retail Consortium. ${ }^{10}$

At the end of March 2002, the UK Treasury reported that the consumer side of the economy continued to be buoyant, with February's retail sales showing the strongest month on month rise since January $2000 .^{11}$ 


\section{A two-speed economy?}

\section{New leisure spending data}

Many commentators, however, have voiced concerns about the sustainability of the so-called 'two-speed' economy, in which weak global demand, domestic manufacturing and private sector investment are offset by strong consumer spending fuelled by low interest rates, rising house prices and unprecedented levels of personal debt. ${ }^{12}$ This apparent dependence of consumer spending growth on ever-growing indebtedness suggests that UK consumer spending would be extremely vulnerable to rising unemployment (which is anticipated) or even small rises in interest rates (which are possible). ${ }^{13}$

\section{Leisure consumer markets}

The performance of domestic leisure markets tends to run in parallel with the consumer market overall, though leisure spending is typically more volatile because of its discretionary nature. ${ }^{14}$

Since September 2001, the Office for National Statistics (ONS) has overhauled the way in which it reports consumer spending on leisure services, to fall into line with EU statistical reporting classifications. ${ }^{15}$ The new data series of most relevance to leisure markets are:

- 'recreation and cultural services', which is a sub-set of the series 'recreation and culture', it covers sports, gambling and cultural destinations - including commercial out of home activities such as health clubs, cinemas and ten-pin bowling - but also museums, swimming pools, the National Lottery and pay-TV services

- restaurants, cafes etc, which covers spending on both food and drink (including alcohol) spent out of the home, and includes take-away meals

- accommodation services, which covers UK hotels and other holiday accommodation.

- foreign tourist expenditure.

These indicators for the period since September 11 show a strong divergence in performance between entertainment ('recreation and cultural services') and eating out on the one hand and tourism and accommodation on the other hand (Figure 1).

According to the ONS, during the last quarter of 2001 spending on 'recreation and cultural services', and 'restaurants, cafes etc' accelerated, following a similar trajectory to that of retail sales discussed earlier. These two sectors of the leisure market were, in fact, among the fastest-growing components of consumer demand, with growth of 2.6 per cent and 4.1 per cent respectively in the September to December period (in current price terms - ie cash to operators).

Additional indicators show that cinema admissions and health and fitness memberships were particularly strong components of the 'recreation and cultural' sector. Cinema admissions were the highest 


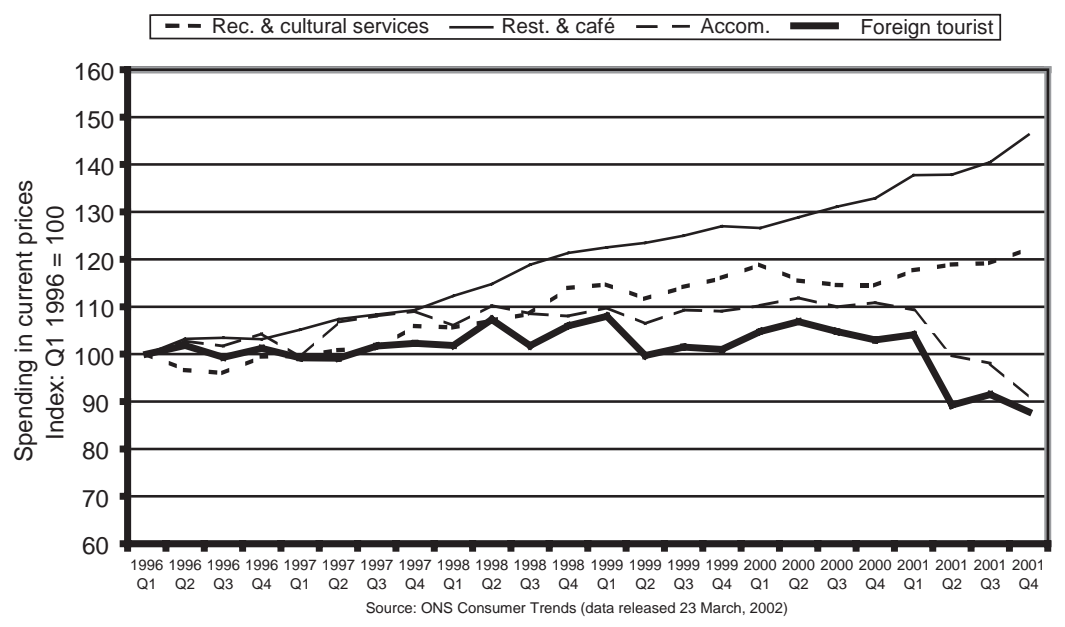

Figure 1: Leisure consumer spending

UK consumers feel wealthy

\section{Tourists visit less}

\section{Weak leisure rental performance in 2001}

for 30 years in 2001, helped by the Harry Potter and Lord of the Rings blockbusters released at the end of the year. ${ }^{16}$ Health and fitness memberships increased by 21 per cent during 2001 according to the Leisure Database Company, which monitors annual performance in the sector. ${ }^{17}$

Like the rest of the domestic consumer market, spending in these entertainment and eating out sectors is being fuelled by households' feelings of being 'cash rich' as a result of low interest rates and low unemployment. Were sentiment to shift suddenly, these leisure markets could be exposed to possibly significant cut backs in expenditure. $^{18}$

In complete contrast, the accommodation sector - which had already been badly affected by the foot-and-mouth crisis earlier in the year - suffered further from the downturn in international tourism after September 11 (Figure 1). The ONS data show a decline of 4.0 per cent in fourth-quarter foreign visitor spend and a 7.2 per cent decline in UK accommodation spending (in current prices). Overall, 2001 was a disastrous year for overseas visitors and the UK accommodation sector, with respective declines in spending of 11.1 per cent and 10.1 per cent over the year (current prices).

\section{THE LEISURE PROPERTY MARKET}

Data coverage of UK leisure property market performance remains poor, with the notable exception of the FPD Savills quarterly Commercial Leisure Survey. ${ }^{19}$ Their February 2002 report provides rental and yield data up to the fourth quarter of 2001. In contrast to the favourable spending trends discussed above, the report indicates weak rental performance during 2001 when compared with the 1998-2000 period. The data show that cinema rents continued their downward trend from the peak in late 1999; bar and restaurant rents also fell in the fourth quarter, continuing the 
Stable conditions and moderate growth predicted trend from late 2000; but health and fitness rents remained stable after a period of strong growth up until 2000.

On the investment side, leisure yields remained stable in the fourth quarter, in line with other property assets, following an outward shift between mid-2000 and mid-2001.

\section{MEDIUM-TERM OUTLOOK}

The economy having avoided recession in 2001, the consensus of UK economists is currently for a moderate slowdown in 2002 followed by stronger growth thereafter. The Treasury's comparison of independent forecasts for the UK economy shows how forecasters became rapidly more pessimistic after September 11, cutting GDP predictions for 2002 by around half a percentage point, and have remained so since. ${ }^{20}$ The latest forecasts (March 2002) indicate GDP growth falling from 2.4 per cent in 2001 to 1.9 per cent in 2002, but then rising to 2.8 per cent in 2003.

The Treasury also monitors medium-term (five year) forecasts from a smaller number of forecasters. ${ }^{21}$ The consensus (in February 2002) indicates moderate, and stable, economic growth ranging from 2.7 per cent per annum to 2.3 per cent per annum during 2003-2006 (Figure 2).

As an earlier paper by this author has argued, stable economic conditions are conducive to strong leisure spending growth because of the relationship between discretionary spending and consumer confidence. $^{22}$ The outlook described in the Treasury survey should therefore benefit the leisure consumer market.

The FPD Savills Commercial Leisure Survey ${ }^{23}$ presents consumer spending forecasts for the key ONS leisure categories identified above (prepared with Business Strategies Ltd (BSL), who are included in the Treasury's survey of independent forecasts). These forecasts, indeed, indicate continuing moderate growth in spending on eating out and 'recreation and cultural services'

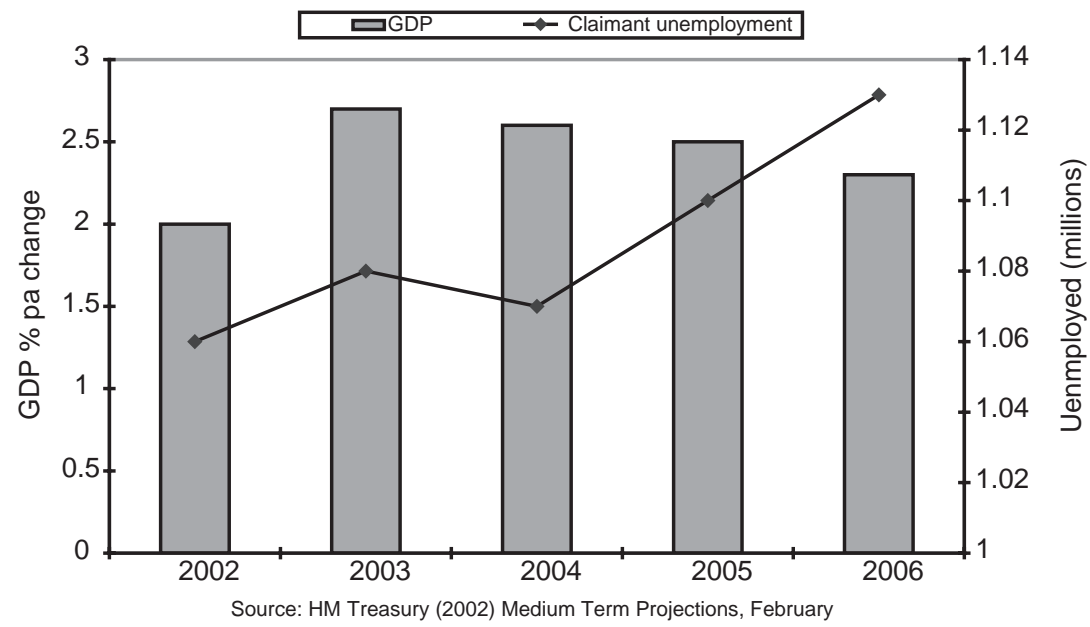

Figure 2: Medium-term projections for the UK economy: Average of independent forecasters 


\section{Short-term uncertainty in leisure property markets}

although foreign tourist expenditure is expected to suffer a further severe decline in 2002 (of almost 20 per cent) with the sector returning to growth only after 2005 . Hotel industry analysts PKF similarly indicate further poor performance of the accommodation sector in London in 2002, though predicting that accommodation demand will recover in $2003 .^{24}$

The few public statements of expectations about commercial leisure property markets indicate mixed views about prospects for 2002. According to Angus McIntosh, chair of the Leisure Property Forum, the UK property market overall can expect rental growth of only 1-2 per cent in 2002, with no increase in capital values. ${ }^{25}$ However, FPD Savills predict upward rental growth in catering and health and fitness properties in 2002, and a recovery in cinema rents in 2003. Surveyors Christie \& Co. suggest stable or modestly rising pub and hotel values in 2002, while Jones La LaSalle Hotels are reported to be indicating renewed investor interest in London hotels towards the end of the year. ${ }^{26}$

\section{LONG-TERM TRENDS IN CONSUMER HABITS}

\section{Visioning the future}

So far, this paper has looked at the immediate and medium-term income prospects for leisure markets. Clearly, these trends are easier to predict with some certainty than are the long-term shifts in social preferences and leisure fashions that will shape the demand for, and obsolescence of, leisure property assets over their lifetime. In thinking about the long term in leisure markets, weeding out the important from the ephemeral is problematical. In this respect, 'futures' analysis provides one possible avenue of enquiry which has attracted ever-greater respectability and popularity in companies and government in recent years (the Cabinet Office, for example, now has its own 'Strategic Thinkers' group and has held a series of expert 'futures' seminars ${ }^{27}$ ). Though this approach is not designed to predict firm outcomes in the way in which empirical forecasting does, scenario building or 'envisioning' helps organisations to prepare for possibly profound shifts in their operating environments, and to identify the 'signposts' (indicators of change) that need to be monitored.

A 'futures' type approach is used in Jones Lang LaSalle's (JLL) recent report 'Leisure 2010 - Experience Tomorrow'28 and was adopted by the RICS Research Foundation in its report '2020 Visions of the Future' which included a separate volume on 'The Future of Leisure'. ${ }^{29}$ The consumer marketing literature, especially from the USA, also provides ample material on the latest qualitative thinking on future wants and needs. ${ }^{30}$

\section{The future in context}

Before summarising some of the key trends identified in this strand of thinking, it is worth stopping to consider how household 
Leisure time has increased in the last 30 years

\section{More time spent shopping and eating out}

behaviour has changed (or not) in the last 30 years, especially in relation to leisure preferences.

Jonathan Gershuny and Kimberly Fisher of the Institute of Social and Economic Research at the University of Essex have analysed trends in leisure habits over many years, drawing on detailed time-diary survey evidence. ${ }^{31}$ Although there is a common perception that modern lives are more harried and less leisured than ever before, their research shows that the average person in the UK had 20 minutes per day more leisure time in 1995 than in 1961. While working hours for full-time employees increased slightly in the 1990s, there has been a continuing decline in the amount of time spent on domestic chores and preparing and eating meals (Figure 3).

However, Gershuny suggests that there is some evidence that individuals now try to fit more activities into their non-work time (which the JLL report also observes), which may contribute to feelings of time pressure. Another important development has been the increasing length of paid holidays, which have risen from under two weeks in the 1950s to four weeks or more in the 1990s.

Shopping and out-of-home leisure have been the main beneficiaries of changing time use, though at the cost of greater time spent travelling (Figure 3). Interestingly, radio/TV time has remained more or less stable despite a massive increase in TV ownership. Households have simply substituted one medium for the other, a finding which raises interesting questions about how new home entertainment media will be consumed in future, and in place of what other leisure activities.

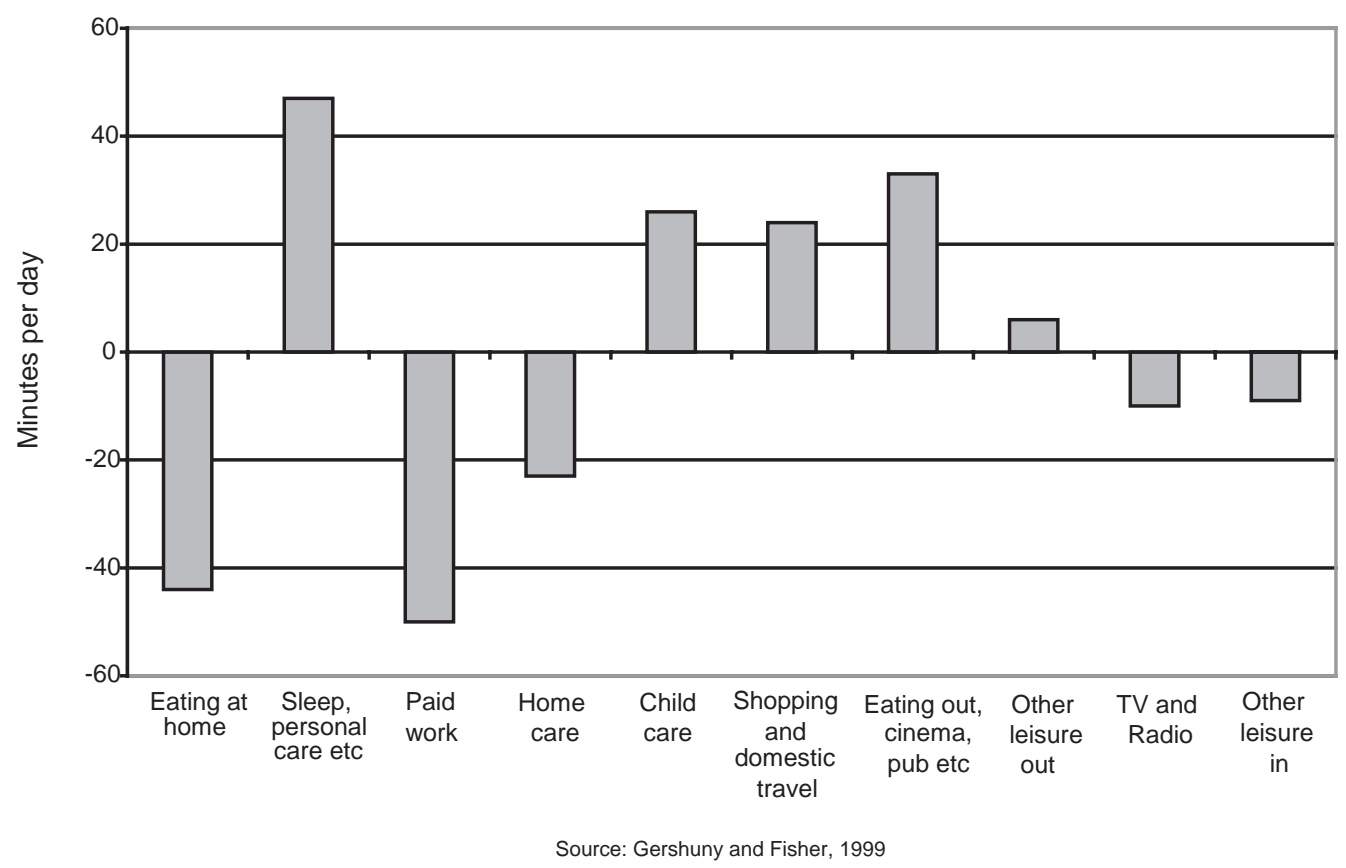

Figure 3: Change in time use, 1961-1995 


\section{Key forces of change}

\section{Alternative visions - a rediscovery of 'quality of life'}

\section{Future possible - Visions and scenarios}

On this point, the JLL report argues that — perhaps counter to popular myth - 'the on-line revolution is not creating a society cocooned in their homes' but is forcing a re-evaluation of how time spent at home is used. The authors suggest that, if anything, leisure time spent out of home is increasing, but is spread ever more thinly across a rising number of activities.

In all, the JLL 'futures' paper identifies ten key forces of change likely to shape future leisure markets. In summary, these forces include:

- a continuing rise in affluence (more for the rich than the poor)

- persistent 'time famine' for affluent consumers

- a growing desire for experiences over products

- willingness to spend beyond income means

- an increasingly self-centred personal outlook

- less secure and spatially more separated personal relationships

- proliferation of consumer choice in which brands help to shortcut decision making

- a shift away from 'youth culture' as the population ages.

The report concludes that the most probable outcome for leisure markets is a 'speeded up' version of the present, in which leisure venues are in continually intense competition for consumers' time and attention. An alternative (but in the authors' view less likely) vision is one in which there is a social backlash against frenetic consumerism and a rediscovery of the 'art of living'.

A similar re-focusing on quality of life was one of the three futures scenarios presented in the RICS Research Foundation 'The Future of Leisure' report. Their 'Social Scene' scenario envisages a world in which values of (environmental) sustainability are central to government policy and become part of the moral mainstream. Specific outcomes include greater restrictions on travel and access to the countryside as well as growing moral pressure to limit tourism. Under this scenario, leisure spending growth is slower, a 'new leisure ethic' favours healthy living over consumption, and leisure activities become more localised, with a particular revival in the use of public leisure venues.

At the other end of the futures spectrum, the report's 'American Dream' scenario envisages high rates of economic growth, less government regulation and a more polarised society with leisure demand focused on experience-rich 'Leisure Grab' offers that can be consumed anywhere, at any time. Holidays are a particular boom sector in this scenario. Meanwhile, the poor become even more dependent on community leisure provision and in-home entertainment.

The central 'Trend' scenario envisages a continuation of present trends in which leisure spending slows slightly as rising welfare demands eat into disposable incomes, but demand for eating out, day visits and overseas holidays continues to grow. 


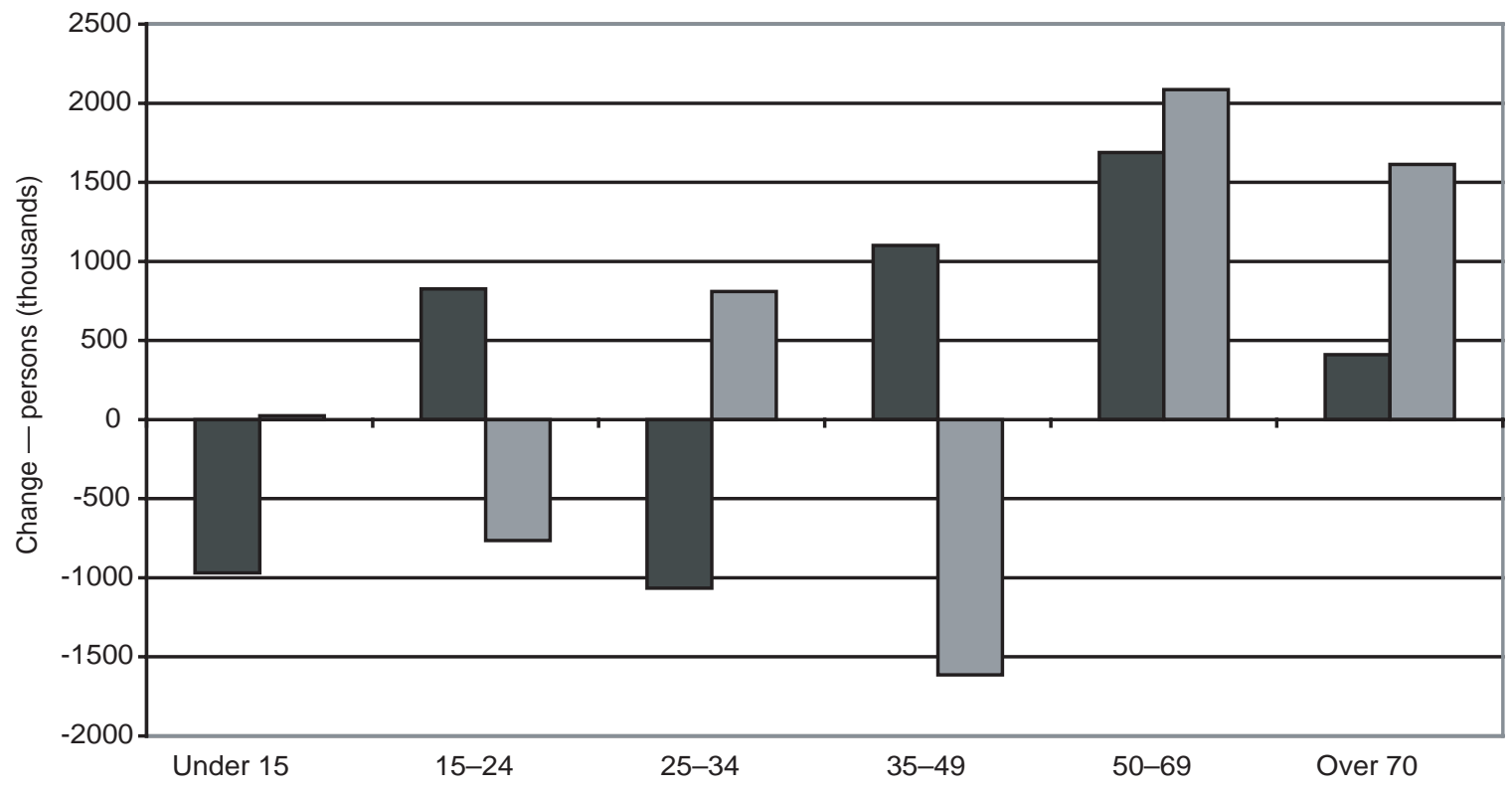

Source: UK mid-2000 population projections prepared by the Government Actuary

Figure 4: The ageing population: Change in population by age group from 2000

\section{Future certain - Ageing consumers}

One theme that all futures work is agreed on, and which is more predictable than most trends, is the ageing of consumers. The latest population projections from the UK Government Actuary show that there will be 2.1 million more over-50s in the next ten years, and a further 3.9 million in the ten years after that (Figure 4). The number of under-35s will drop by just over 1 million over the same 20 years, and by 2020 there will be as many consumers aged over 70 as there are aged $25-34$.

As many commentators point out, these new older people will most probably have better health as well as very different tastes and aspirations from their parents, the current elderly. Nor are they likely to want an 'aged' version of existing leisure offers. The consensus is that these will be 'active elders' with ample disposable income who may be more hedonistic than is commonly supposed. Some, for example, may even be willing to consume their children's inheritance to fulfil experiences that were not available during their youth (the term 'SKINS' - spend the kids' inheritance now - has been used in the USA to describe this baby-boom generation). ${ }^{32}$

\section{Active elders} Other pointers to the future habits of 'mature' consumers include: working for longer but more intermittently; substantial demand for holidays and short breaks; a desire to maintain well-being through strength-building exercise; more loneliness and searching for opportunities to socialise (and even date); and participating with grandchildren on holidays and leisure activities. ${ }^{33}$ 


\section{IMPLICATIONS FOR LEISURE PROPERTY}

Recent empirical analysis confirms the continuing growth of leisure consumer markets in the UK, while forecasts indicate a stable, though moderate, outlook for spending growth in the next five years. The continuing willingness of UK consumers to spend beyond their means, however, remains a constant underlying risk to the stability of consumer markets.

Over the long term, ageing of the population is the clearest and most predictable trend that will influence the shape of leisure demand. There is, however, only limited evidence on the ground that operators and leisure investors are paying more than lip service to this crucial trend. The 'mature' market appears to be treated in the UK as one undifferentiated bloc whose preferences are assumed to be largely tame, straightforward and predictable. Trends emerging from the USA, however, suggest that the substantial range of wants from the over-50s will be novel and diverse, and that this age group — as they have done before in the 1960s — will set new rules for social behaviour which could change the way society thinks about leisure.

Other leisure futures work has also uncovered 'signposts' to trends which could challenge the 'more and faster is better' orthodoxy. Alternative visions of the future point towards a more convivial and moralistic set of social preferences focused on improving 'quality of life'. Such a trend could have profound implications for the way in which leisure time is perceived and used, and make many existing leisure offers redundant.

This diverse range of possibilities for fads, fashions and habits clearly presents enormous challenges to owners and managers of leisure properties that were built to last.

\section{References}

1. This paper updates and expands on some of the material presented in a similar paper in this journal one year ago: Cox, J. (2001) 'Leisure property trends: Consumer market and behaviour,' Journal of Leisure Property, Vol. 1, No. 3, pp. 277-286.

2. BBC News Online, $27^{\text {th }}$ September, 2001, www.bbc.co.uk

3. Reported by BBC News Online. Survey available on subscription from GFK Martin Hamblin.

4. Mansfield, K (2001) 'Testing times', Leisure Management, November/December 2001, Leisure Media Company, Hitchin.

5. See www.ey.com/global/gcr.nsf/uk/news_room_-_press_release_-_hotels

6. The Times (2002), 20 February, p. 4.

7. Mansfield, K (2001), ref 4 above.

8. International Passenger Survey reported in EGI Daily Headlines www.egi.co.uk

9. Office for National Statistics, 'Consumer Trends', available only on the Internet at www.statistics.gov.uk.

10. Reported in King Sturge (2002) 'Retail \& Leisure Research Bulletin, 2002 Quarter 1', see www.kingsturge.co.uk.

11. HM Treasury, 'Weekly Economic Indicators', posted on the Treasury website at www.hm-treasury.gov.uk.

12. See, for example, Bank of England (2001) 'Financial Stability Review', December, and various on-line discussions, for example on the www.ft.com website. 
13. Schurich, C. (2002) 'Underlying Factors 2001 Q4', in ONS 'Consumer Trends Quarter 4 2001', No. 23, which provides detailed data and discussion on the reasons for currently strong consumer spending, as well as the resulting risks. See www. statistics.gov.uk.

14. See Cox, ref. 1 above, for a discussion of the relationship between the consumer economy and leisure spending.

15. The changes are explained on the www.statistics.gov.uk website.

16. Sources: ONS; AC Nielsen EDI at www.entdata.com/bonews/freign/frgn_tpc.html ; and the Cinema Advertising Association figures reported in Leisure and Hospitality Business, 21 March, 2002.

17. Leisure Database Company (2001) 'The State of the Industry Report' available on 020 7379 3197. Headline findings were reported in Fitness Focus, Leisure and Hospitality Business, November 2001.

18. This risk is highlighted in Ernst \& Young (2002) 'UK Restaurants, What Stakeholders Need to Know', see www.ey.com/global/gcr.nsf/UKReal_Estate_-_Library.

19. Available on request from Mat Oakley at FPD Savills on 0207409 8781. Details of the report are also available at www.fpdsavills.co.uk.

20. HM Treasury (2002) 'Forecasts for the UK Economy: A Comparison of Independent Forecasts, March 2002', Available on the Treasury website www.hm-treasury.gov.uk.

21. HM Treasury (2002) 'Medium Term Projections, February 2002'. Also available on the Treasury website, www.hm-treasury.gov.uk.

22. Cox, ref. 1 above.

23. FPD Savills, ref. 19 above.

24. PKF (2002) 'London trends 2002', reported in Leisure and Hospitality Business 21 March.

25. McIntosh, A. (2002) 'Tough times ahead', LPF comment in Leisure Management, March.

26. FPD Savills, ref. 19 above; Christie \& Co (2001) 'Business Review 2001: Business Outlook 2002', Jones Lang La Salle, 'Hotel Investment Strategy Annual', quoted by Chris Curtis in Leisure and Hospitality Business, 12 February, 2002, p. 2.

27. See, for example, Cabinet Office Performance and Innovation Unit (2001) 'Short Survey of Published Material on Key UK Trends: 2001-2011', http://www.cabinetoffice.gov.uk/innovation/2001/futures/main.shtml.

28. Jones Lang LaSalle (2001) 'Leisure 2010 - Experience Tomorrow', available on the LPF website to members and from Jones Lang LaSalle European Leisure Group. See www.lpf.org.uk.

29. Evans, C. and Morley, S. (2000) 'The Future of Leisure', one of a series of reports produced as part of the RICS Research Foundation '2020 Visions of the Future' series, RICS Research Foundation, London. See also, in the same series, Cooper, I. (2000) 'Preparing for the Future: A User's Guide', which explains the futures and scenario building approach.

30. See, for example, work by Faith Popcorn such as Popcorn, F. and Hanft, A. (2001) 'Dictionary of the Future', Hyperion Books, New York, and commentary by the Consumer Trends Institute at www.trendsinstitute.com. In the UK, the Henley Centre provides similar insights at www.henleycentre.com.

31. Gershuny, J. and Fisher, K. (1999) 'Leisure in the UK across the $20^{\text {th }}$ Century', Institute of Social and Economic Research Working Paper, University of Essex.

32. Maguire, A. (2001) 'Boomers are blooming', Leisure Management, October.

33. See, for example, Henley Centre, 'Grey Expectations', at www.henleycentre.com/press; Howells, R. (2001) 'Golden opportunity', Health Club Management, November; Consumer Trends Institute (2001) 'Consumer Trends Report: Ageing of the Population', July, see www.trendsinstitute.com; www.thirdage.com; Jones Lang LaSalle, ref. 28 above. 